\title{
THEORIES OF THE CAUSES OF POVERTY*
}

Key words: Poverty, Poor, Inequality, Theory, Power Resources, Social Policy

David Brady

University of California, Riverside \& WZB Berlin Social Science Center

Forthcoming in Annual Review of Sociology

October 14, 2018

Word Count (excluding title page, abstract, supplements, references \& figures): 7582

* Direct correspondence to David Brady, School of Public Policy, University of California, INTS 4133, 900 University Ave., Riverside, CA 92521; email: dbrady@ucr.edu. 


\title{
THEORIES OF THE CAUSES OF POVERTY
}

\begin{abstract}
There has been a lack of debate between and frameworks for theories of the causes of poverty. This essay proposes that most theories of poverty can be productively categorized into three broader families of theories: behavioral, structural, and political. Behavioral theories concentrate on individual behaviors as driven by incentives and culture. Structural theories emphasize the demographic and labor market context, which causes both behavior and poverty. Political theories contend that power and institutions cause policy, which causes poverty, and moderates the relationship between behavior and poverty. I review each theory's arguments, contributions and challenges. Further, I explain how to integrate, classify studies into, and distinguish between theories. Ultimately, I argue that poverty research would benefit from more explicit theory and theoretical debate, as well as greater interdisciplinarity and integration between studies of the U.S., rich democracies, and developing countries.
\end{abstract}


Thirty years ago, in The Journal of Economic Literature, Sawhill (1988: 1085, 1113) decried the lack of theory in poverty research: "We are swamped with facts about people's incomes and about the number and composition of people who inhabit the lower tail, but we don't know very much about the process that generates these results. . From a more scientific perspective, we still understand very little about the basic causes of poverty. . . until more complete theories and models of the process by which income is generated and distributed are developed and tested, the answers to some of the questions raised in this article must remain partial and tentative.”

Thirty years later, poverty research continues to lack clear theory. There are few explicitly named "theories", and little explicit theoretical debate. If a theory of the causes of poverty is articulated, it is usually only compared against the null hypothesis of no effect. Studies rarely compare two or more theories against each other. Even more than other fields, poverty researchers often focus on descriptive or normative claims without explaining poverty's causes (Desmond \& Western 2018). It remains unclear if poverty is simply a subset of status attainment or if it can be explained by broader theories of the income distribution.

Also inhibiting theoretical progress, poverty research is deeply fragmented. There is far too little interdisciplinary and international conversation even though poverty research exists in several disciplines and most countries (Brady \& Burton 2016). Poverty researchers often study only one case with little effort to generalize beyond the case. Indeed, American poverty research tends to focus solely on the U.S., and often just a few Northern U.S. cities. Relatedly, there are too few connections between literatures on the U.S., on other rich democracies, and on developing countries. This is the case even though these literatures are all interested in similar questions about the nature, causes and effects of poverty. 
Altogether, the lack of theory undermines the field's cumulative progress towards understanding poverty. A lack of theory prevents understanding of what scholars have in common, how they differ, what the alternative explanations are, and what is new and not new. All of this erodes the scientific community as scholars reinvent the wheel, talk past each other, and overlook how their work builds on others.

Desmond \& Western's (2018) Annual Review of Sociology illustrates these problems. ${ }^{1}$ Unfortunately, a seriously reading of the poverty literature reveals that their "new directions" are not actually new. Rather, their framing of novelty results from missed connections to wellestablished theories and literatures. They criticize, “conceiving of poverty as a trait that characterizes individuals and families;” but do not acknowledge the many prior critiques of individualism (e.g. Rank 2005). They promote "A relational perspective [that] views poverty. . .as the outcome of power relations. . .expressed through a political process that institutionalizes" the collective decisions of rich democracies. However, they do not even mention the vast power resources literature, which has been providing exactly such a perspective for decades (see "Political Theories" section below). Finally, they overlook how their exclusive focus on the U.S. can bias impressions about the causes of poverty.

Such problems exist partly because, and unlike most fields, the poverty field lacks summaries of leading theories of the causes of poverty. To the best my knowledge, there has never been an Annual Review essay on the theories of the causes of poverty. There have been

\footnotetext{
${ }^{1}$ As another example, Bertrand and colleagues (2004) frame their "behavioral economic view of poverty" as between a standard economic rational actor approach and a "culture of poverty" explanation focused on deviant culture. However, they provide zero citations for cultural explanations (also Dahl et al. 2014), and cultural theorists will likely view their presentation as a caricature. Indeed, Bertrand and colleagues' behavioral economic view is very similar to new cultural explanations.
} 
several handbooks (Banerjee et al. 2006; Brady \& Burton 2016; Jefferson 2012; Lohmann \& Marx 2018), and review essays on aspects of poverty (Desmond \& Western 2018; Hoynes et al. 2006; McEwen \& McEwen 2017; Sawhill 1988). Yet, with a few exceptions (e.g. Gordon 1972), there is a striking dearth of overviews of social science theories of the causes of poverty.

This essay addresses that need. I contend poverty research needs more clarity and explicit debate on theories of the causes of poverty. In turn, I propose that most explanations can be productively categorized into three broader families of theories: behavioral, structural, and political. For each, I summarize the arguments, contributions, and challenges. Further, the essay explores how to integrate the theories, classify studies into theories, and distinguish between theories. Ultimately, the essay encourages poverty researchers to be more theoretically engaged.

Before proceeding, it is important to note the essay's scope conditions. I focus on causes

and not effects (except when effects reproduce and then cause poverty). Also, there is no space to discuss poverty measurement (poverty is defined simply as a shortage of resources relative to needs). For all theories, there are underlying and fundamental causes outside view (e.g. structural theories focused on economic development need not explore all causes of economic development). Hence, the theories concentrate on reasonably proximate factors.

\section{THEORY IN POVERTY RESEARCH}

By “theory”, I simply mean a general framework with core principles and concepts that enable: (a) predictions and specific testable implications across a range of settings; and/or (b) explanation of specific cases. The most useful theories are accompanied by research programs that explain an expanding set of cases and are able to reconcile anomalous cases without abandoning core principles. Ideally, theories of poverty are: exportable outside initial cases or 
samples; have both internal and external validity; are fruitful and generate subsequent research;

and are clear. Concretely, a theory should explain why some are poor and others are not, and why poverty is greater in one setting than another.

Explanations of the causes of poverty can be classified into three broad families of theories: behavioral, structural and political. ${ }^{2}$ Behavioral theories concentrate on individual behaviors as driven by incentives and culture. Structural theories emphasize the demographic and labor market context, which causes behavior and poverty. Political theories contend that power and institutions cause policy, which causes poverty and moderates the relationship between behavior and poverty. To enhance understanding, I graphically display the three theories to highlight the relationships that have accumulated the most research and evidence. ${ }^{3}$ Although most explanations can be classified into one of these three, debate certainly should occur on this schema and the names of the three. ${ }^{4}$

\section{BEHAVIORAL THEORIES}

\section{Contributions}

Behavioral theories are represented in Panel A of Figure 1. In these theories, behavior is the key mechanism directly causing poverty (AEI-Brookings 2015; Sawhill 2003). According to this explanation, the poor are poor because they engage in counter-productive, poverty-

\footnotetext{
${ }^{2}$ Notably, the literature on beliefs about the causes of poverty categorizes beliefs into sets of explanations that are similar to this framework (Hunt \& Bullock 2016).

${ }^{3}$ Figure 1 does not specify every possible relationship, and omissions are usually potential directions where there is a scarcity of research. Further, the figures and text imply causal theoretical relationships even though the literature does not necessarily provide causal evidence. ${ }^{4}$ I do not review every conceivable explanation. As a decision rule, I exclude any that have failed to generate progressive research programs, even though some are visible or classics (e.g. Marxist [Gordon 1972], functional [Gans 1995], and genetics).
} 
increasing behavior or "risks" like single motherhood or unemployment (Bertrand et al. 2004; Durlauf 2011). Poverty is high in a context because there is a high prevalence of those with demographic characteristics indicating such behaviors (Cruz \& Ahmed 2018; Kaida 2015; Ku et al. 2018; Milazzo \& van de Walle 2017). According to behavioralists, for example, racial disparities in poverty result from a disproportionate amount of problematic behavior among racial minorities. To reduce poverty, we need to reduce the prevalence of people engaging in such behaviors (AEI-Brookings 2015; Jencks 1992; McLanahan 2009).

\section{[ FIGURE 1 ABOUT HERE ]}

Reflecting behavioral theory, many use individual-level datasets to study low-income mothers and fathers, and investigate why they conceive children out of wedlock and do not get married (Burton et al. 2009; Gibson-Davis et al. 2005; Lichter et al. 2003; McLanahan 2009). Consistent with behavioral theories, risks like single motherhood, low education, and unemployment, are significantly associated with poverty in many settings (Kohler et al. 2012; Rainwater \& Smeeding 2004). For example, Brady \& colleagues (2017) show that in 28 of 29 rich democracies, unemployment predicts poverty.

Major versions of behavioral theories tend to present incentives and culture as the principal sources of behavior (Bertrand et al. 2004; Durlauf 2011). By incentives, scholars emphasize rational responses of goal-oriented individuals that result in problematic behavior. By culture, the focus has been on schemas and repertoires that guide the poor's behavior. The literature on behavioral causes of poverty also often allows for interactions between incentives and culture (see Dohan 2003; Harding 2010).

For a long time, poverty scholars have investigated how incentives shape the poor's behavior (Katz 2013; Levine 2013; Lichter et al. 2003; O’Connor 2001, 2016). Much research 
tests whether generous social policies trigger moral hazards and welfare dependency, and disincentivize against poverty-reducing behaviors like work and marriage. For instance, many conclude that the 1996 U.S. welfare reforms successfully encouraged employment and reduced single motherhood (Bitler et al. 2006; Moffitt 2002).

Regarding developing countries, there has been much less interest in whether generous social policies encourage moral hazards. Rather, scholars typically focus on how market inefficiencies and problematic policies disincentivize poor people from investing in productive activities (Bertrand et al. 2004; Duflo 2006; Ravallion 2016). For example, because market inefficiencies discourage the poor from investing in insurance (Banerjee \& Duflo 2011), adverse life events like accidents are more strongly associated with descents into poverty (Krishna 2011). This work on the incentives to behavior to poverty relationship in developing countries dovetails with the robust literature showing that expansions of education and reductions of fertility substantially lower poverty (Brady et al. 2007; Hannum \& Xie 2016; Sen 1999). Indeed, education, especially of young women, is one of the most powerful anti-poverty behaviors globally (Deaton 2013; Nussbaum 2004).

One particularly visible recent behavioral theory is the "new" culture of poverty literature (Harding 2010; Lamont \& Small 2008; Streib et al. 2016). This literature purports to offer a more nuanced interpretation of culture than older culture of poverty theories. However, the core arguments are very similar (Steinberg 2011; Streib et al. 2016). ${ }^{5}$ Culture explains the

\footnotetext{
${ }^{5}$ Just like the new, the old recognized the probabilistic and reciprocal relationship between culture and poverty (O’Connor 2001). Harding (2010) criticizes the old for treating poor culture as homogenous oppositional norms/values rather than heterogeneous frame/scripts. However, his text mainly concentrates on mean differences in culture/behavior of disadvantaged versus nondisadvantaged neighborhoods. Harding (2010) writes: "Boys in poor neighborhoods are presented with many negative role models" (p.67); “Adolescent boys who have little or no relationship with their fathers, the norm in poor neighborhoods, are particularly susceptible to the
} 
counterproductive behavior that causes poverty (Dahl et al. 2014). Small and colleagues' (2010: 6) aim is "explicitly explaining the behavior of low-income population in reference to cultural factors," and demonstrating how culture and behavior are, "processes and mechanisms that lead to the reproduction of poverty" (p.23). This literature investigates, "whether the cultural models and motives that the poor internalize might have an 'exogenous explanatory power' that serves to inhibit socioeconomic success” (Vaisey 2010: 96). For example, Harding (2010) argues poor neighborhoods are more culturally heterogeneous, which causes problematic adolescent male sexual, violent, and educational behavior, which presumably then causes poverty.

Behavioral scholars also explore how poverty reciprocally feeds back into behavior to reproduce poverty intra- and intergenerationally (indicated by the dashed lines in Panel A of Figure 1). Poverty imposes a cognitive burden, present bias, and stress, which then encourages poverty-perpetuating behavior, such as lower educational attainment (Gennetian \& Shafir 2015; Hannum \& Xie 2016; McEwen \& McEwen 2017; McLoyd et al. 2016; Mullainathan \& Shafir 2013). As well, poverty undermines children's cognitive ability and development (Guo \& Harris 2000; Sharkey 2013), which undermines education and leads to adult poverty. Often these feedbacks result from poverty causing problematic incentives or culture (Dahl et al. 2014). The theory of "poverty traps" is an argument that poverty creates bad incentives that undermine motivations for and returns to investments that could reduce subsequent poverty, such as education or insurance (Banerjee \& Duflo 2011; Carter \& Barrett 2006; Carter \& Lybbert 2012;

influence of older peers" (p.104); and "Compared to their counterparts. .., the boys [in poor neighborhoods] approach romantic relationships with a great deal of distrust” (p.172). In actuality, the empirical implications are very similar in the old and new. Harding (2010) argues poor neighborhoods have simultaneous heterogeneity of "good" and "bad", the good is diluted by the bad, and all of this "levels expectations." In practice, the new empirical implications (nonpoor are homogenously good while poor are a heterogeneous mix of good and bad) are very close to the old (i.e. poor have a higher share of bad to good). 
Gennetian \& Shafir 2015). For example, there is a poverty trap if modest investments in education cause an opportunity cost of lower earnings, and poverty only declines with unfeasibly high investments in education (Ravallion 2016). Further, scholars argue that culture is a response to poverty, which then discourages education, employment and marriage of the poor or encourages welfare dependency or out of wedlock births (Dahl et al. 2014; Harding 2010).

\section{Challenges}

Despite its contributions, this literature faces several challenges. First, behavioral explanations are rarely compared against the evidence for any alternative theory. Most just aim to demonstrate culture/incentives/behavior matter and no rival explanation is considered. Indeed, few even compare incentives against culture as causes of poverty-increasing behavior.

Second, although behavioral theories often feature strong causal claims, there remains tremendous uncertainty about causality (Streib et al. 2016). Scholars routinely fallaciously imply that describing "who is poor" provides an explanation of the causes of poverty (Gans 1995; Katz 2013; Rank 2005; Ryan 1976; Schwartz \& Carpenter 1999). ${ }^{6}$ While acknowledging behavior and poverty are reciprocally related, the new culture literature has made little progress untangling the causal order (Steinberg 2011). ${ }^{7}$ If culture and poverty are reciprocally related, this leads to a

${ }^{6}$ This was best illustrated by Rank (2011: 19): "Picture a game with ten players, but only eight chairs. When the music stops, who's most likely to be left standing? It will be those who are at a disadvantage in terms of competing for the available chairs (less agility, reduced speed, a bad position when the music stops, and so on). However, given that the game is structured in a way such that two players are bound to lose, these individual attributes only explain who loses, not why there are losers in the first place. Ultimately, there are simply not enough chairs for those playing the game. The critical mistake that's been made in the past is that we 've equated the question of who loses at the game with the question of why the game inevitably produces losers. They are, in fact, distinct and separate questions.”

${ }^{7}$ If the new culture of poverty literature solely sought to explain the consequences of poverty, this would be less of a problem. However, the literature routinely studies outcomes (e.g. teen pregnancy, non-marriage, school incompletion, and unemployment) that are important because they lead to poverty, and aims to explain the reproduction of poverty. 
rather obvious endogeneity problem that fails to explain what causes poverty in the first place (Gans 1995; Katz 2013; Ryan 1976). ${ }^{8}$ Indeed, behavioral theories are unclear about whether their arguments are even intended to be causal. Small and colleagues (2010: 15) write, "Rather than causing behavior, frames make it possible or likely;” even though there is no real difference between "cause” and "make possible or likely.” This confusion about causality partly results from a lack of comparative research designs that would facilitate stronger causal claims (Streib et al. 2016). Although culture of poverty scholars argue culture and context are pivotal, there are few cross-cultural and truly cross-contextual studies.

Third, the relationship between behaviors and poverty is quite unreliable (Andreß et al. 2006; Rothwell \& McEwen 2017). For example, although single motherhood has been the most widely studied risk of poverty, Brady and colleagues (2017) show that single motherhood is not even significantly associated with poverty in 19 of 29 rich democracies. Indeed, Bloome (2017) shows that among children in low-income families, there is no disadvantage in upward mobility associated with single parenthood. Although many presume unemployment and single motherhood cause child poverty in the U.S., Baker (2015) demonstrates that poverty's association with employment has increased dramatically while its association with marriage has declined dramatically since the 1970s.

Fourth, relatedly, behavioralists have been unable to explain macro-level variation in poverty (Heuveline \& Weinshenker 2008; Rainwater \& Smeeding 2004). The cross-national prevalence of risks cannot explain cross-national variation in poverty (Brady et al. 2017). One

\footnotetext{
8 These kinds of critiques are not new (Gans 1995; Katz 2013; O’Connor 2001; Ryan 1976; Steinberg 2011). Yet, recent cultural theorists have largely sidestepped these critiques while constructing a narrative that cultural explanations fell out of favor because of political correctness. Plausibly, however, cultural explanations declined partly because of the persuasiveness of critiques like these (and other logical and evidentiary problems).
} 
reason behavior explanations have been so prominent despite these limitations is that much of the research linking behavior to poverty has been done in the U.S. or unique settings with weak welfare states (Ku et al. 2018). For behavioral research to move forward, there is a clear need for more international research. Generally, the central, and potentially intractable, question for behavioral theories is why they are unable to explain macro-level variation in poverty (Brady 2009; Gans 1995; Schwartz \& Carpenter 1999).

Fifth, although incentive-behavior accounts have long contended that generous social policies encourage counterproductive behavior, much recent research contradicts this claim. Many show that the 1996 U.S. welfare reform did not discourage single motherhood (Fitzgerald and Ribar 2004). Although Moffitt (2002) argued earlier that welfare reform successfully promoted marriage and employment, he (2015: 745) later concludes:

The evidence shows that neither work disincentives nor family structure incentives are large in magnitude, especially in the aggregate. . . the aggregate effect on earnings in the low-income population is almost zero. . . As for family structure incentives, a large body of research. . .failed to show any major effects on the fraction of single-mother families. . Research on the effects of the 1996 reform of the program on family structure also has shown very mixed results and no evidence of any major effect.

As well, a rapidly growing international literature contradicts claims that generous social policies incentivize poverty-increasing behavior (Biegert 2017; Brady et al. 2017; Milazzo \& van de Walle 2017; Ravallion 2016; Salehi-Isfahani \& Mostafavi-Dehzooei 2018). For instance, Banerjee and colleagues (2016) analyze seven random control trials across less developed countries, and find no effects of conditional or unconditional cash transfers on employment. The claim that generous social policies incentivize poverty-increasing behavior has been central to behavioral theories for a very long time (Katz 2013; O’Connor 2001). This is because disincentives have been the key reason behavioralists caution against generous social policies 
and instead advocate for behavior change. In turn, this evidence fundamentally challenges a core principle of behavioral theories.

\section{STRUCTURAL THEORIES}

\section{Contributions}

In structural theories of poverty, "structure” refers to macro- and meso-level demographic and economic contexts representing available opportunities and constraints (Rank 2005, 2011; Tomaskovic-Devey 1991; Wilson 1987, 1996). Panel B of Figure 1 shows that structural theories focus on how demographic and economic contexts cause poverty through three channels. First, indirectly, structural contexts cause problematic behavior, which causes poverty. Second, these structures directly cause poverty, even net of behavior. Third, structural contexts interact with behavior to moderate the behavior-poverty relationship. Hence, structuralists differ from behavioralists because economic and demographic contexts do not solely operate through behavior. Also, structuralists tend to highlight the contextual effects of demographic/economic structures while behavioralists tend to focus on demographic/economic composition. According to structuralists, for example, racial disparities in poverty are caused by differential exposure to deleterious structural contexts. Economic context typically includes economic growth and development, industrialization and deindustrialization, and spatial and skills mismatches. Demographic context usually includes neighborhood disadvantage, age/sex composition, residential segregation, urbanization and demographic transitions.

Structural theories have a long history, and may be the most subscribed to theory in sociology (O’Connor 2001, 2016). These theories partly originate from scholars like Clark (1965), who were trying to explain deep-seated racial inequalities in the U.S. (Sugrue 1996) 
Around the same time, scholars like Harrington (1981) and Galbraith (1998) stressed how economic growth was not helping, and often was displacing, the poor. Structural theories gained momentum as scholars sought to explain concentrated inner-city poverty in the 1980s (Allard 2017; Massey 2016; O’Connor 2016; Pattillo \& Robinson 2016; Sugrue 1996; Wilson 1987, 1996). These literatures parallel longstanding interest in the benefits of economic development for poor countries, as well as literatures on labor market segmentation (Gordon 1972; Tomaskovic-Devey 1991), and rural and suburban poverty (Allard 2017; Lichter et al. 2012).

The most prominent structural account in American sociology is the literature on concentrated urban disadvantage and neighborhood effects (Ananat 2011; Massey 2016; Owens 2015; Sharkey 2013; Sugrue 1996). Following Wilson (1987, 1996), many show how deindustrialization and skill/spatial mismatches cause joblessness (Mouw 2000), family change (Harknett \& McLanahan 2004; Wodtke 2013), and poverty. Some debate the relative salience of residential segregation versus deindustrialization/joblessness, while others stress their interactions (Crowder \& South 2005; Lichter et al. 2012; Pattillo \& Robinson 2016). For instance, Massey and Fischer (2000) argue that economic change interacts with residential segregation to cause the concentration of urban poverty (Ananat 2011; Massey 2016; Iceland \& Hernandez 2017; Quillian 2012; Tach \& Emory 2017). Neighborhood effects scholars show that concentrated poverty then becomes a structural cause of behavior and poverty (Harding 2010; Harknett \& McLanahan 2004; Rendon 2014; Wodtke 2013). For instance, Sharkey (2013) demonstrates that growing up in segregated and concentrated poor neighborhoods exposes children to stress (e.g. through violence), which undermines education and attainment (e.g. by weakening cognitive ability and mental health), and causes subsequent poverty. 
Another prominent structural explanations emphasizes how economic development reduces poverty in developing countries (Brady et al. 2007; Collier 2006; Wade 2016). Development creates jobs and access to and returns to schooling, and encourages urbanization, better health and lower fertility (Ravallion 2016). As a result, economic development strongly reduces poverty (Deaton 2013; Wade 2016). For instance, Ravallion \& Chen (2007) show that economic development and urbanization explain China's massive decline in poverty in recent decades. Indeed, economic growth is often presented as a necessary condition for reducing poverty in developing countries (Collier 2006). This literature highlights the undeniably salient facts like that Sub-Saharan Africa's lack of economic growth explains its persistently high poverty, or that China probably accomplished the largest reduction in poverty in the shortest time in world history (Deaton 2013; Wade 2016). As Collier (2006: 190) writes: “Growth is not a cure-all, but the lack of growth is a kill-all.”

Across rich democracies, structural changes like deindustrialization and rising female labor force participation influence poverty (Brady 2009; Moller et al. 2003). Many also link the structural context of economic performance to poverty. Economic growth increases labor demand, raises wages, and lifts the bottom of the labor market (Blank 2000; Sawhill 1988). In multi-level models of individual and country-level predictors of individual-level poverty, individual-level employment is consistently one of the most powerful predictors (Brady et al. 2017). As Rainwater and Smeeding (2004: 133) write, “The most important step in reducing poverty among children is to ensure that at least one parent is employed.” Because individuallevel employment is influenced by the structural economic context (e.g. the business cycle), structural economic context likely has a large indirect effect on individual poverty. Conversely, other structuralists emphasize that the poor are marginalized by economic growth (Fodor \& Horn 
2015; Galbraith 1998; Harrington 1981). Such scholars criticize the focus on economic performance because it neglects how the returns to economic performance are highly stratified.

\section{Challenges}

Structuralists are presently confronting at least three challenges. First, although structuralists highlight contextual effects more than behavioralists, they remain quite focused on behavior. In many studies, the independent variable is a structural change and the dependent variable is a behavior presumed to cause poverty. Therefore, the challenges facing behavioralists also apply here. Rather than presuming behaviors cause poverty, the literature needs to demonstrate that structure causes behavior and behavior causes poverty.

Second, partly because structural theory is so popular (especially in sociology), there is a lack of coherence among the varied accounts under the structural banner. Indeed, many behavioralists claim to view structure as the underlying cause of poverty, or claim culture is a mechanism between structure and behavior. Ethnographies often preview a structural theory in the introduction, but do not actually analyze structural variation, or exclusively concentrate on individual-level behavior (Contreras 2012). In studies of intergenerational poverty, poverty is said to cause a problematic culture, which causes problematic behavior and subsequent poverty. Yet, most studies of intergenerational poverty do not actually bring structure back in as there is no arrow from poverty back to structure. Instead, they just start with the poor's problematic culture without ever really proving that poverty causes structure or structure causes culture. ${ }^{9}$

\footnotetext{
${ }^{9}$ An exception might be those who say poverty causes some structural context, which then causes behavior and poverty. For example, some argue poverty causes a weak marriageable male market, which causes single motherhood, which causes poverty (Gibson-Davis et al. 2005; Harknett \& McLanahan 2004; Lichter et al. 2003). Again, however, the section on challenges for behavioral theories suggests the last step (single motherhood to poverty) is questionable.
} 
This is not simply a matter of culture or behavior scholars focusing on a smaller piece of a bigger structural theory. The problem is there is a misalignment between the professed structural theory and what the research design can leverage. As a result, there is a misallocation of attention in the field away from actual structural explanations. Ultimately, a study advancing a genuine structural theory needs to do two things. First, it needs to incorporate substantial variation in structural contexts into the design. Second, it needs to explain: how structure causes culture/behavior and that culture/behavior causes poverty; or that poverty causes structure and structure causes culture/behavior and that culture/behavior causes poverty. Otherwise, there is little coherence to the various arguments under the structural banner.

Third, the effects of structures appear to vary across time and place. For example, it is well known that economic development reduces poverty in less developed countries. Nevertheless, the benefits of economic development have diminished in recent decades (Brady et al. 2007). Similarly, there are large, stable differences in poverty across rich democracies even though all experienced similar structural changes like deindustrialization and rising female labor force participation. This variation in the effects of structures suggests that politics and institutions may moderate whether and how structures cause poverty. To the extent that states can alleviate the impact of demographic and economic contexts, political theories may provide a better explanation of the causes of poverty.

\section{POLITICAL THEORIES}

\section{Contributions}

Political theories contend that poverty is a political outcome driven by power relations over and collective choices about how to distribute resources (for a review of political theories, 
see Brady et al. 2016). Political theories are displayed in Panel C of Figure 1. These theories contend that power and institutions cause policy, which causes poverty and moderates the behavior-poverty link. Power and institutions reinforce each other, and institutions also directly shape poverty and moderate the behavior-poverty link. ${ }^{10}$ While Desmond \& Western (2018) neglect political explanations, and emphasize micro-level relations over macro-level power and institutions, well-developed political theories largely precede their relational approach.

Arguably, the most influential political explanation is power resources theory (Brady 2009; Huber \& Stephens 2001; Korpi 1983). Power resources theory contends that collective political actors mobilize less advantaged classes around shared interests and ideology. Such groups then form labor unions (Brady et al. 2013; Lohmann 2009; Rosenfeld \& Laird 2016), elect Left parties (Huber and Stephens 2012), and expand the welfare state (Nelson 2012). The mobilization of less advantaged groups is pivotal because the default distribution of political power in a capitalist democracy favors elites and business. This default power advantage leads to a default high level of inequality. Hence, it is essential for the working-class and poor to bond together and attract some of the middle class to gain any real political power. Power resources theory is often used to explain why some welfare states are more generous than others. However, power resources theory is actually a broader theory of the income distribution, with the welfare state as a principal mechanism. Power resources theory has evolved over time (Brady et al.

\footnotetext{
${ }^{10}$ As noted above, many factors drive institutions and power. Ideology/interests (Hunt \& Bullock 2016; Watkins-Hayes \& Kovalsky 2016) and mobilization (Levine 2016; Piven \& Cloward 1993; Piven \& Minnite 2016; Trejo 2016) can reasonably be folded within political theories (Brady 2009). For example, many show racism undermines support for generous social policies (Gilens 1999). In turn, racism works through power resources and policies as a fundamental, underlying cause of poverty (Michener 2018). Unlike behavioral theories, there is less concern that power and institutions are endogenous to poverty.
} 
2016), and has become more focused on institutionalized power (e.g. electoral systems, stable democracy) (Brady 2009; Huber and Stephens 2012) than its earlier versions (Korpi 1983).

Poverty is lower in rich democracies where Left parties have controlled government, unionization is higher, and women are a greater share of parliaments (Brady 2009; Moller et al.2003). In Latin America, Leftist governments in periods of stable democracy resulted in generous social policies and lower poverty (Huber \& Stephens 2012). In multilevel models of individuals within the U.S., working poverty is significantly lower in states with higher unionization (Brady et al. 2013). This literature demonstrates more than just a negative association between Leftist politics and welfare generosity and poverty. Rather, most crucial is that the effects of Leftist politics and welfare generosity appear to be much larger than individual behavior or structural factors (Brady 2009; Brady et al. 2017).

A second influential political explanation focuses on how institutions, such as regulations and laws, govern the distribution of economic resources (Brady et al. 2016; Pernia \& Deolalikar 2003). This literature highlights that poverty rates are stable and slow-moving and do not quickly respond to elections and changes in power. There is considerable path dependency to poverty and to understand the institutional sources, we need a long time horizon of causes and effects (O’Connell 2012). Institutions reflect the residue of the power of collective actors in the past, and institutions continue to be consequential even without active maintenance by collective actors. For instance, historical institutions like slavery (O’Connell 2012) and federalism (Allard 2017; Michener 2018) contribute to the perpetuation of racial inequalities in poverty. A strong institutionalism claims that historically established institutions dominate over contemporary politics to lock in poverty. A weaker institutionalism claims that historically established institutions guide how and when politics can shape poverty (Huber \& Stephens 2001). 
Although the institutional literature is less crystalized than the power resources literature, there are several research streams. ${ }^{11}$ First, scholars link poverty to electoral institutions (Brady 2009). For example, stable, long-term democratization is associated with lower poverty (Huber \& Stephens 2012; Sen 1999). Second, labor market and educational institutions are associated with poverty (Moller et al. 2003). For example, working poverty is significantly lower where wage-bargaining is coordinated, centralized, and corporatist, and employment contracts are protected (Giesselmann 2014; Lohmann 2009; Lohmann \& Marx 2018). Third, historical institutions like slavery and colonialism disadvantage poor countries and perpetuate poverty (Acemoglu \& Robinson 2012; Bhattarcharya 2016). For instance, Nunn (2008) demonstrates how four major slave trades over 500 years impoverished African countries through the mechanisms of political instability, corruption, bad governance, ethnic fragmentation, and economic underdevelopment (but see Bhattacharyya 2016). Bhattarcharya (2016) explains that geography, climate and disease conditions selected countries into different colonial institutions, which shaped long-term economic development, with consequences for contemporary poverty (Acemoglu \& Robinson 2012). Such historical institutions help explain why the global economic hierarchy of countries is so remarkably stable - the countries that were rich and poor a century ago remain rich and poor today (Wade 2016).

Across the political literature on poverty, there is a central role for state policies (Aizer et al. 2016; Atkinson 2015; Barrientos 2013; Brady 2009; Fodor \& Horn 2015; Fox et al. 2015; Korpi \& Palme 1998). Brady \& colleagues (2016) catalogue the generic mechanisms for how states shape poverty: (a) organizing the distribution of resources (e.g. taxes and transfers, often

\footnotetext{
${ }^{11}$ Some also draw an arrow from institutions/policies back to behavior. However, these are largely behavioral explanations of poverty (e.g. a policy discourages marriage).
} 
called "redistribution”); (b) insuring against risks; (c) investing in capabilities (e.g. early childhood education and health services); (d) allocating opportunities (e.g. public employment); (e) socializing normative expectations; and (f) disciplining the poor. State policies also matter to racial inequalities in poverty because of both differential access to and differential effects of social policies (Michener 2018; Soss et al. 2011; Watkins-Hayes \& Kovalsky 2016).

Recently, there are several emerging developments on the welfare state (Atkinson 2015; Brady \& Bostic 2015). First, there is growing interest in how welfare generosity entails both: (a) formally legislated coverage, replacement rates, and eligibility criteria (Scruggs \& Allan 2006); and (b) "takeup”, access and barriers to programs and services (Shaefer 2010). Second, scholars study dimensions of social policies, such as targeting and universalism (Jacques \& Noel 2018; Korpi \& Palme 1998; Marx et al. 2016; Scruggs \& Allan 2006). Third, moving beyond rich democracies, there is growing interest in social policy and poverty in developing countries (Barrientos 2013; Huber \& Stephens 2012). Fourth, returning to Panel B of Figure 1, scholars increasingly show how social policies moderate the behavior-poverty link (Andreß et al. 2006; Barbieri \& Bozzon 2016; Brady et al. 2017; Gornick \& Jäntti. 2012; Kohler et al. 2012; Misra et al. 2012; Vandecasteele 2011). The relationships between poverty and behaviors like single motherhood are significantly weaker in generous welfare states (Rothwell \& McEwen 2017). Such risks are penalized more severely in weak welfare states like the U.S., and uncorrelated with poverty in generous welfare states like Denmark (Brady et al. 2017). This accumulating evidence challenges the behavioralist core principle that there is necessarily a relationship between behaviors and poverty. Instead, how strongly behaviors are related to poverty is a political decision about how much a society chooses to employ social policy to weaken the "penalty" associated with a behavior. 
Beyond welfare generosity, scholars have long studied how states discipline, regulate, supervise and displace the poor (Katz 2013; O’Connor 2001; Piven \& Cloward 1993). Although recent scholars often neglect that these themes have been in poverty scholarship for a long time, there has been growing interest in how “disciplining institutions” constrain the poor (Desmond \& Western 2018; Edwards 2016; Seim 2017; Soss et al. 2011; Stuart 2016; Wacquant 2009). For example, housing displacement - facilitated by state and local governments - compounds disadvantages associated with poverty (Purser 2016; Sullivan 2017). Although social policies reduce poverty and weaken the behavior-poverty link, other aspects of social policies have long been used to control and punish the poor (Piven \& Cloward 1993; Soss et al. 2011). Perhaps the most visible theme in the disciplining institutions literature is how incarceration exacerbates poverty (Gottlieb 2017; Turney 2015; Wacquant 2009). For example, Wildeman (2014) shows that paternal incarceration increases child homelessness.

\section{Challenges}

There has been increasing momentum for political explanations in recent decades. Yet, this literature also faces challenges. First, while power resources scholars show that Left parties and labor unions benefit the poor, these organizations appear to be weakening in a wide variety of settings (Brady et al. 2016). If these organizations serve the interests of the poor, it is unclear why they are struggling to build solidarity and mobilize the disadvantaged more than in the past

(Piven \& Minnite 2016). Relatedly, even when holding power, there is evidence that the Left has become less effective over time at expanding the welfare state (Huber \& Stephens 2001).

Second, while many aim to identify if a specific social policy has a causal effect (Aizer et al. 2016; Bitler et al. 2015; Bitler \& Karoly 2015; O’Brien \& Robertson 2018; Sosnaud 2016), the comparative social policy literature has long emphasized how social policies actually work 
together in complementary and interdependent configurations. Scholars are only beginning to analyze how social policies shape poverty amidst the myriad interactions with other policies and institutions (Biegert 2017; Giesselmann 2014). Going forward, scrutiny is needed of how the broader political context shapes the effects of social policies. We need to balance the priority for internal validity with a commitment to external validity, which implies understanding how social policies implicitly interact with political and institutional contexts.

Third, research on disciplining institutions tends to study one institution at a time in isolation, and often makes strong claims about the effects on poverty. However, these institutions are confounded with and only prominent in weak welfare states, and perhaps mostly the U.S. (Gottlieb 2017; Wacquant 2009). It is unclear how large the effects of disciplining institutions are net of and relative to beneficial social policies. As well, it is unclear how much disciplining institutions cause poverty compared to other unobserved political factors that are correlated with disciplining institutions. For example, Gottlieb (2017) shows that cross-national variation in poverty is not significantly associated with incarceration after controlling for welfare generosity. Although disciplining institutions certainly disproportionately harm racial minorities and women, those groups were more likely to be poor before many disciplining institutions grew so powerful, and might still be more likely to be poor even if those institutions did not exist. As a result, we do not truly understand how much of racial and gender inequality in poverty is driven by these institutions. For example, the victims of eviction are likely to be poor regardless of whether they are evicted (Brady et al. 2017), so it is entirely plausible that eviction is a symptom rather than a cause of poverty (Purser 2016). Going forward, the literature on disciplining institutions should engage political theories, make fewer bold claims, and embrace a more balanced perspective about the broader political causes of poverty (Brady et al. 2016). Rather than having uniquely 
large effects on poverty, disciplining institutions are probably best understood as embedded in and interacting with several other political factors (Edwards 2016; Purser 2016; Stuart 2016).

\section{APPLYING THE FRAMEWORK}

For this framework to be most useful, it is important to clarify the links between these theories and empirical research. This section discusses how to integrate the theories, how to classify studies into theories, and how to distinguish between theories.

\section{Integrating Theories}

Realistically, it may facilitate a more complete understanding of poverty to incorporate multiple causes and integrate several theories. After all, the panels of Figures 1 could be nested into one comprehensive model. Indeed, poverty scholars often offer productive syntheses (Dohan 2003; Levine 2013; Wilson 1996). For example, Wilson (1996) unites behavioral (e.g. cultural adaptation), structural (e.g. deindustrialization), and political (e.g. social policies) factors. Critiquing behavioral explanations, Rank’s $(2005,2011)$ structural account and the structural violence perspective (Rylko-Bauer \& Farmer 2016) combine structural and political theories. As well, scholars often employ all three theories in one study. For example, Owens (2015) demonstrates how racial and class segregation (i.e. structural) interacts with housing policy (i.e. political) and both interact with individual residential choices (i.e. behavior) to concentrate poverty in neighborhoods. The key goals for synthetic explanations should be to be: (a) coherent rather than self-contradictory; (b) substantially more effective/predictive than an explanation focused on one set of causes; and (c) still reasonably parsimonious rather than encyclopedic.

\section{Classifying Studies}


To understand the theoretical implications of empirical research more clearly, one can classify studies according to this essay's framework. Instead of attributing hidden motivations, we should probably focus on objectively assessing the arguments. Readers can ask where the "action" is, and what is most consequential in the explanation. Readers can content analyze where the text is focused, where attention is concentrated, and where the spotlight is shined. Even if a text professes a theory in the introductory chapter, the paramount question is on what factors the bulk of the text concentrates. The reader should ask what the author would change if s/he could change only a few factors to reduce poverty. If the author had a magic wand, where would they intervene to make the biggest possible difference to poverty? Would it be behavior, structure, or politics? This magic wand metaphor helps us concentrate on what is most salient to poverty in magnitude, and not just identifying a statistically significant causal effect. This also helps scholars align research designs with questions about what causes are most salient.

\section{Distinguishing Between Theories}

Figure 2 identifies the salient distinctions between theories. This helps one assess how a given set of results inform theories. This can also facilitate the design of studies for the explicit purpose of comparing and adjudicating between theories.

\section{[ FIGURE 2 ABOUT HERE ]}

First, the distinction between structural and behavioral explanations hinges on the question: how much are behaviors beyond individual control and dictated by structure? If individuals lack agency in the face of overwhelming structural changes like economic development, structure is more important than behavior. If individuals exert great control on whether they are poor even in structurally disadvantaged contexts, behavioral explanations remain essential despite the relevance of structural factors. 
Second, political theories can be distinguished from behavioral theories principally by asking: how much can governments moderate the behavior-poverty link? If states can choose whether and how much a given individual characteristic, such as single motherhood, is associated with poverty, this supports political over behavioral explanations. If risks like unemployment trigger poverty regardless of the social policy and institutional context, this favors behavioral explanations over political explanations.

Third, political theories can be distinguished from structural theories by asking: how much can governments moderate the effects of demographic and labor market contexts? If states cannot manage to reduce poverty in the face of deindustrialization or absent economic development, for example, structure matters more than politics. If states can accomplish low poverty regardless of economic development or demographic change, politics matter more than structure. While sociologists often combine political and structural factors (e.g. Rank 2005, 2011), there is a profound difference between demographic and economic changes that are beyond the control of governments, and the political choices governments can and do make to ameliorate poverty. While structuralists view poverty as the unfortunate byproduct of contextual factors that overwhelm what can be done, political accounts view poverty as the willfully chosen outcome of state (in)action when something could be done.

\section{CONCLUSION}

Poverty research has not been sufficiently theoretical and the lack of theoretical debate and explicit theory undermines the field. This essay encourages poverty researchers to be more theoretically engaged, to consciously debate between theories, and to explicitly compare evidence against theories. More theoretical engagement will facilitate greater cumulative, 
interdisciplinary and international scientific progress, will better clarify what is new and not new, and will facilitate breaking out of our disciplinary and national parochialism.

The essay proposes that most explanations of poverty can be productively categorized into three broader families of theories: behavioral, structural, and political. Behavioral theories concentrate on individual behaviors as driven by incentives and culture. Structural theories emphasize the demographic and labor market context, which causes both behavior and poverty. Political theories contend that power and institutions cause policy, which causes poverty, and moderates the relationship between behavior and poverty. Poverty scholars should debate this schema of three theories, the names and coherence of each, and how to classify studies into theories. Although this author proposes this particular schema might be productive, it is more important that vibrant theoretical debates take place among poverty scholars.

Theories of causes should be at the center of poverty research. If not, the field will face the same dilemmas Sawhill (1988) diagnosed thirty years ago. In focusing on theories of causes, this essay differs from Desmond \& Western's (2018) focus on description and normative values. While many poverty scholars share their values and few dispute the role for description, humanizing descriptions are an insufficient substitute for theories of causes. Regardless of how much compassion or "moral urgency" a text induces, it does not follow that this clarifies what causes poverty or how we should intervene on it. There is a long history of viewing poverty as an "affront to dignity" and still blaming the poor for their plight. Indeed, emphasizing description of injustices instead of theories of causes misdirects attention to poverty's symptoms instead of its underlying causes. Finally, rather than branding one’s own work as a "new direction" (Desmond \& Western 2018), poverty scholars should do more to recognize the similarities between their explanations and well-established theories within the field. Focusing on theories of causes will 
make the commonalities between explanations more explicit. Recognizing how one's account has origins in, builds on, or breaks away from existing theories will also clarify how and where we are making progress in understanding poverty. The social science of poverty has existed for a long time, and understanding our shared perspectives will make the field stronger. 


\section{SUMMARY POINTS}

- There has been a lack of debate between and frameworks for theories of the causes of poverty.

- Most explanations of poverty can be productively categorized into three broader families of theories: behavioral, structural, and political.

- Greater scientific progress in poverty research would occur with more explicit theory, as well as greater interdisciplinarity and integration between studies of the U.S., rich democracies, and developing countries.

- Behavioral theories concentrate on individual behaviors as driven by incentives and culture.

- Structural theories emphasize the demographic and labor market context, which causes both behavior and poverty.

- Political theories contend that power and institutions cause policy, which causes poverty, and moderates the relationship between behavior and poverty.

\section{FUTURE ISSUES LIST}

- It would be productive for the poverty research community to debate the schema of three theories, the names and coherence of each theory, and how to classify arguments and studies into these three theories.

- Behavioral explanations should be compared empirically against alternative theories, and cultural and incentive arguments should be compared as explanations of behavior.

- There is a need for behavioral research that is cross-cultural, cross-contextual, and international, and that explains macro-level variation in poverty.

- Structural theory should aim for greater coherence and for a closer alignment between professed structural theories and what the research design can leverage.

- Political theories should study both the causal effects of specific policies, and how policies are complementary with and interact with political/institutional contexts.

\section{ACKNOWLEDGEMENTS}

The author thanks the following for suggestions: Regina Baker, Jason Beckfield, Lonnie Berger, Katie Bolzendahl, Maria Cancian, Rich Carpiano, John Eason, Katy Fallon, Ryan Finnigan, Marco Giesselmann, Eric Grodsky, Herbert Kitschelt, Bruce Link, Stephanie Moller, Alfonso Morales, Rourke O’Brien, Zach Parolin, Heike Solga, Seymour Spilerman, John Stephens, Bruce Western, the AAM workshop at the WZB, UCR students in Public Policy 234, The UCR Blum Initiative California Poverty Fellows, and audiences at the University of Wisconsin Institute for Research on Poverty, and the Inequality Workshop at the Center for European Studies at the University of North Carolina at Chapel Hill. I also thank editor Doug Massey and an anonymous reviewer. 


\section{LITERATURE CITED}

Acemoglu D, Robinson JA. 2012. Why Nations Fail New York: Crown

AEI-Brookinigs. 2015. Opportunity, Responsibility, and Security: A Consensus Plan for

Reducing Poverty and Restoring the American Dream. Washington, D.C.: American

Enterprise Institute for Public Policy Research and the Brookings Institution

Aizer A, Eli S, Ferrie J, Lleras-Muney A. 2016. The Long-Run Impact of Cash Transfers to Poor Families. American Economic Review. 106: 935-971

Allard SW. 2017. Places in Need. New York: Russell Sage Foundation.

Ananat EO. 2011. The Wrong Side(s) of the Tracks: The Causal Effects of Racial Segregation on Urban Poverty and Inequality. American Economic Journal: Applied Economics. 3: 3466

Andreß H-J, Borgloh B, Bröckel M, Giesselmann M, Hummelsheim D. 2006. The Economic Consequences of Partnership Dissolution - A Comparative Analysis of Panel Studies from Belgium, Germany, Great Britain, Italy and Sweden. European Sociological Review. 22: 533-560

Atkinson AB. 2015. Inequality - What Can Be Done? Cambridge, MA.: Harvard University Press

Baker RS. 2015. The Changing Association Among Marriage, Work, and Child Poverty in the United States, 1974-2010. Journal of Marriage and Family. 77: 1166-1178

Banerjee AV, Be’nabou R, Mookherjee D, eds. 2006. Understanding Poverty New York: Oxford University Press

Banerjee AV, Duflo E. 2011. Poor Economics. New York: Public Affairs

Banerjee, AV, Hanna R, Kreindler G, Olken BA. 2016. Debunking the Stereotype of the Lazy Welfare Recipient: Evidence from Cash Transfer Programs. Working Paper

Barbieri P, Bozzon R. 2016. Welfare, Labour Market Deregulation and Households' Poverty Risks: An Analysis of the Risk of Entering Poverty at Childbirth in Different European Welfare Clusters. Journal of European Social Policy. 26: 99-123

Barrientos A. 2013. Social Assistance in Developing Countries. New York: Cambridge University Press

Bertrand M, Mullainathan S, Shafir E. 2004. A Behavioral Economics View of Poverty American Economic Review 94: 419-423.

Bhattacharyya S. 2016. The Historical Origins of Poverty in Developing Countries. In The Oxford Handbook of the Social Science of Poverty, ed. D Brady, LM Burton, pp. 270292. Oxford University Press

Biegert T. 2017. Welfare Benefits and Unemployment in Affluent Democracies: the Moderating Role of the Institutional Insider/Outsider Divide. American Sociological Review. 82: 1037-1064.

Bitler MP, Gelbach JB, Hoynes HW. 2006. Welfare Reform and Children’s Living Arrangements. Journal of Human Resources. 41: 1-27

Bitler MP, Karoly LA. 2015. Intended and Unintended Effects of the War on Poverty: What Research Tells Us and Implications for Policy. Journal of Policy Analysis and Management. 34: 639-696

Blank RM. 2000. Fighting Poverty: Lessons From Recent U.S. History. Journal of Economic Perspectives 14: 3-19

Bloome D. 2017. Childhood Family Structure and Intergenerational Income Mobility in the United States. Demography. 54: 541-569 
Brady D. 2009. Rich Democracies, Poor People. New York: Oxford University Press

Brady D, Baker RS, Finnigan R. 2013. When Unionization Disappears: State-Level Unionization and Working Poverty in the U.S. American Sociological Review. 78: 872-896

Brady D, Blome A, Kleider H. 2016. How Politics and Institutions Shape Poverty and Inequality. In The Oxford Handbook of the Social Science of Poverty, ed. D Brady, LM Burton, pp. 117-140. New York: Oxford University Press

Brady D, Bostic A. 2015. Paradoxes of Social Policy: Welfare Transfers, Relative Poverty and Redistribution Preferences. American Sociological Review. 80: 268-298

Brady D, Burton LM, eds. 2016. The Oxford Handbook of the Social Science of Poverty. New York: Oxford University Press

Brady D, Finnigan R, Hübgen S. 2017. Rethinking the Risks of Poverty: A Framework for Analyzing and Comparing Prevalences and Penalties. American Journal of Sociology. 123: $740-786$

Brady D, Kaya Y, Beckfield J. 2007. Reassessing the Effect of Economic Growth on Well-Being in Less Developed Countries, 1980-2003. Studies in Comparative International Development. 42: 1-35

Burton LM, Cherlin A, Winn D-M, Estacion A, Holder-Taylor C. 2009. The Role of Trust in Low-Income Mothers’ Intimate Unions. Journal of Marriage and Family 71: 1107-1124

Carter MR, Barrett CB. 2006. The Economics of Poverty Traps and Persistent Poverty: An Asset-Based Approach. Journal of Development Studies. 42: 178-199

Carter MR, Lybbert TJ. 2012. Consumption Versus Asset Smoothing: Testing the Implications of Poverty Trap Theory in Burkina Faso. Journal of Development Economics 99: 255264.

Clark KB. 1965. Dark Ghetto. New York: Harper and Row

Collier P. 2006. The Bottom Billion. New York: Oxford University Press

Contreras R. 2012. The Stickup Kids. Berkeley: University of California Press

Crowder K, South SJ. 2005. Race, Class, and Changing Patterns of Migration Between Poor and Nonpoor Neighborhoods. American Journal of Sociology. 110: 1715-1763

Cruz MS, Ahmed A. 2018. On the Impact of Demographic Change on Economic Growth and Poverty. World Development 105: 95-106

Dahl GB, Kostol AR, Mogstad M. 2014. Family Welfare Cultures. The Quarterly Journal of Economics 129: 1711-1752

Deaton A. 2013. The Great Escape. Princeton University Press

Desmond M, Western B. 2018. Poverty in America: New Directions and Debates. Annual Review of Sociology 44: 1-25.

Dohan D. 2003. The Price of Poverty. Berkeley: University of California Press

Duflo E. 2006. Poor but Rational? In Understanding Poverty, ed. AV Banerjee, R Be’nabou, D Mookherjee, pp. 367-378. New York: Oxford University Press

Durlauf SN. 2011. Groups, Social Influences and Inequality. In Poverty Traps, ed. S Bowles, SN Durlauf, K Hoff, pp. 141-175. Princeton: Princeton University Press.

Edwards F. 2016. Saving Children, Controlling Families. American Sociological Review. 81: 575-595

Fitzgerald J, Ribar D. 2004. Welfare Reform and Female Headship. Demography. 41: 189-212

Fodor E, Horn D. 2015. “Economic Development” and Gender Equality: Explaining Variations in the Gender Poverty Gap After Socialism. Social Problems 62: 286-308. 
Fox L, Wimer C, Garfinkel I, Kaushal N, Waldfogel J. 2015. Waging War on Poverty: Poverty Trends Using a Historical Supplemental Poverty Measure. Journal of Policy Analysis and Management. 34: 567-592

Galbraith JK. 1998. The Affluent Society. New York: Mariner Books

Gans HJ. 1995. The War Against the Poor. New York: Basic Books

Gennetian LA, Shafir E. 2015. The Persistence of Poverty in the Context of Financial Stability: A Behavioral Perspective. Journal of Policy Analysis and Management. 34: 904-936

Gibson-Davis, CM, Edin K, McLanahan S. 2005. High Hopes but Even Higher Expectations: The Retreat from Marriage among Low-Income Couples. Journal of Marriage and Family. 67: 1301-1312

Giesselmann M. 2014. The Impact of Labour Market Reform Policies on Insiders’ and Outsiders’ Low-Wage Risk. European Sociological Review. 30: 549-561

Gilens M. 1999. Why Americans Hate Welfare. Chicago: University of Chicago Press

Gordon D. 1972. Theories of Poverty and Underemployment. Lexington, MA: Lexington Books

Gornick J, Jäntti M. 2012. Child Poverty in Cross-National Perspective: Lessons from the Luxembourg Income Study. Children and Youth Services Review. 34: 558-568

Gornick JC, Smeeding TM. 2018. Redistributional Policy in Rich Countries: Institutions and Impacts in Nonelderly Households. Annual Review of Sociology 44:

Gottlieb A. 2017. Incarceration and Relative Poverty in Cross-National Perspective: The Moderating Roles of Female Employment and the Welfare State. Social Service Review. 91: 293-318

Guo G, Harris KM. 2000. The Mechanisms Mediating the Effects of Poverty on Children's Intellectual Development. Demography. 37: 431-447

Hannum E, Xie Y. 2016. Education. In The Oxford Handbook of the Social Science of Poverty, ed. D Brady, LM Burton, pp. 462-485. Oxford University Press

Harding D. 2010. Living the Drama. Chicago: University of Chicago Press

Harknett K, McLanahan SS. 2004. Racial and Ethnic Differences in Marriage After the Birth of a Child. American Sociological Review. 69: 790-811

Harrington M. 1981. The Other America. NY: Penguin

Heuveline P, Weinshenker M. 2008. The International Child Poverty Gap: Does Demography Matter? Demography. 45: 173-191

Hoynes HW, Page ME, Stevens AH. 2006. Poverty in America: Trends and Explanations. Journal of Economic Perspectives. 20: 47-68

Huber E, Stephens JD. 2012. Democracy and the Left. Chicago: University of Chicago Press 2001. Development and Crisis of the Welfare State. Chicago: University of Chicago Press

Huber E, Stephens JD, Bradley D, Moller S, Nielsen F. 2009. The Politics of Women's Economic Independence. Social Politics. 16: 1-39

Hunt MO, Bullock HE. 2016. Ideologies and Beliefs About Poverty. In The Oxford Handbook of the Social Science of Poverty, ed. D Brady, LM Burton, pp. 93-116. Oxford University Press

Iceland J, Hernandez E. 2017. Understanding Trends in Concentrated Poverty: 1980-2014. Social Science Research. 62: 75-95

Jacques O, Noel A. 2018. The Case for Welfare State Universalism, Or the Lasting Relevance of the Paradox of Redistribution. Journal of European Social Policy 28: 70-85

Jefferson, PN. 2012. The Oxford Handbook of the Economics of Poverty New York: Oxford University Press 
Jencks C. 1992. Rethinking Social Policy. New York: Harper

Kaida L. 2015. Ethnic Variations in Immigrant Poverty Exit and Female Employment: The Missing Link Demography 52: 485-511.

Katz MB. 2013. The Undeserving Poor, $2^{\text {nd }}$ Edition. New York: Oxford University Press

Kohler U, Ehlert M, Grell B, Heisig JP, Radenacker A, Wörz M. 2012. Verarmungsrisiken Nach Kritischen Lebensereignissen in Deutschland und den U.S.A Kölner Zeitschrift für Soziologie und Sozialpsychologie. 64: 223-245

Korpi W. 1983. The Democratic Class Struggle. Boston: Routledge.

Korpi W, Palme J. 1998. The Paradox of Redistribution and Strategies of Equality: Welfare State Institutions, Inequality, and Poverty in the Western Countries. American Sociological Review. 63: 661-687

Krishna A. 2011. One Illness Away. New York: Oxford University Press

Ku I, Lee W, Lee S, Han K. 2018. The Role of Family Behaviors in Determining Income Distribution: The Case of South Korea. Demography. 55: 877-899.

Lamont M, Small M. 2008. How Culture Matters: Enriching Our Understandings of Poverty. In The Colors of Poverty, ed. D Harris, A Lin, pp. 76-102. New York: Russell Sage Foundation

Levine JA. 2013. Ain't No Trust Berkeley, CA: University of California Press

Levine JR. 2016.Community-Based Organizations as Nonelected Neighborhood Representatives. American Sociological Review. 81: 1251-1275

Lichter DT, Parisi D, Taquino MC. 2012. The Geography of Exclusion: Race, Segregation and Concentrated Poverty. Social Problems. 59: 364-388

Lichter DT, Graefe DR, Brown JB. 2003. Is Marriage a Panacea? Union Formation Among Economically Disadvantaged Unwed Mothers. Social Problems. 50: 60-86

Lohmann H. 2009. Welfare States, Labor Market Institutions and the Working Poor: A Comparative Analysis of 20 European Countries. European Sociological Review. 25: 489-504

Lohmann H, Marx I, eds. 2018. Handbook of Research on In-Work Poverty. Northampton, MA.: Edward Elgar

Marx I, Salanauskaite L, Verbist G. 2016. For the Poor, But Not Only the Poor: On Optimal ProPoorness in Redistributive Policies. Social Forces. 95: 1-24

Massey DS. 2016. Segregation and the Perpetuation of Disadvantage. In The Oxford Handbook of the Social Science of Poverty, ed. D Brady, LM Burton, pp. 370-393. Oxford University Press

Massey DS, Fischer MJ. 2000. How Segregation Concentrates Poverty. Ethnic and Racial Studies. 23: 670-691

McEwen CA, McEwen BS. 2017. Social Structure, Adversity, Toxic Stress, and Intergenerational Poverty: An Early Childhood Model. Annual Review of Sociology. 43: 445-472

McLanahan SS. 2009. Fragile Families and the Reproduction of Poverty. Annals of the American Academy of Political and Social Science. 621: 111-131

McLoyd VC, Jocson RM, Williams AB. 2016. Linking Poverty and Children's Development: Concepts, Models, and Debates. In The Oxford Handbook of the Social Science of Poverty, ed. D Brady, LM Burton, pp. 141-165. Oxford University Press

Michener J. 2018. Fragmented Democracy. New York: Cambridge University Press 
Milazzo A, van de Walle. D 2017. Women Left Behind? Poverty and Headship in Africa. Demography. 54: 1119-1145

Misra J, Moller S, Strader E, Wemlinger E. 2012. Family Policies, Employment and Poverty Among Partnered and Single Mothers. Research in Social Stratification and Mobility. 30: 113-128

Moffitt RA. 2015. The Deserving Poor, the Family, and the U.S. Welfare System. Demography 52: $729-749$ 2002. From Welfare to Work: What the Evidence Shows. The Brookings Institution Policy Brief, Welfare Reform \& Beyond No. 13

Moller S, Bradley D, Huber E, Nielsen F, Stephens JD. 2003. Determinants of Relative Poverty in Advanced Capitalist Democracies. American Sociological Review. 68: 22-51

Mouw T. 2000. Job Relocation and the Racial Gap in Unemployment in Detroit and Chicago, 1980 to 1990. American Sociological Review. 65: 730-753

Mullainathan S, Shafir E. 2013. Scarcity. New York: Times Books

Nelson K. 2012. Counteracting Material Deprivation: The Role of Social Assistance in Europe. Journal of European Social Policy 22: 148-163

Nunn N. 2008. The Long-Term Effects of Africa's Slave Trades. Quarterly Journal of Economics. 123: 139-176

Nussbaum M. 2004. Women’s Education: A Global Challenge. Signs. 29: 325-355.

O’Brien RL, Robertson CL. 2018. Early-Life Medicaid Coverage and Intergenerational Economic Mobility. Journal of Health and Social Behavior. In press

O’Connell HA. 2012. The Impact of Slavery on Racial Inequality in Poverty in the Contemporary U.S. South. Social Forces. 90: 713-734

O’Connor A. 2016. Poverty Knowledge and the History of Poverty Research. In The Oxford Handbook of the Social Science of Poverty, ed. D Brady, LM Burton, pp.169 -192. Oxford University Press . 2001. Poverty Knowledge. Princeton: Princeton University Press

Owens A. 2015. Housing Policy and Urban Inequality: Did the Transformation of Assisted Housing Reduce Poverty Concentration. Social Forces. 94: 325-348

Pattillo M, Robinson JN III. 2016. Poor Neighborhoods in the Metropolis. In The Oxford Handbook of the Social Science of Poverty, ed. D Brady, LM Burton, pp. 342-268. Oxford University Press

Pernia E, Deolalikar A, eds. 2003. Poverty, Growth and Institutions in Developing Asia. New York: Palgrave Macmillan

Piven FF, Cloward R. 1993. Regulating the Poor. New York: Vintage

Piven FF, Minnite LC. 2016. Poor People's Politics. In The Oxford Handbook of the Social Science of Poverty, ed. D Brady, LM Burton, pp. 751-773. Oxford University Press

Purser G. 2016. The Circle of Dispossession: Evicting the Urban Poor in Baltimore. Critical Sociology 42: 393-415

Quillian L. 2012. Segregation and Poverty Concentration: The Role of the Three Segregations. American Sociological Review. 77: 354-379

Rainwater L, Smeeding TM. 2003. Poor Kids in a Rich Country. Russell Sage Foundation

Rank MR. 2011. Rethinking American Poverty. Contexts. 10: 16-21 2005. One Nation, Underprivileged. New York: Oxford University Press

Ravallion M. 2016. The Economics of Poverty. New York: Oxford University Press 
Ravallion M, Chen S. 2007. China’s (Uneven) Progress Against Poverty. Journal of Development Economics. 82: 1-42

Rendon MG. 2014. “'Caught Up’: How Urban Violence and Peer Ties Contribute to High School Noncompletion.” Social Problems 61: 61-82

Rosenfeld J, Laird J. 2016. Unions and Poverty. Pp. 800-819 in The Oxford Handbook of the Social Science of Poverty, ed. D Brady, LM Burton. Oxford University Press

Rothwell DW, McEwen A. 2017. Comparing Child Poverty Risk by Family Structure During the 2008 Recession. Journal of Marriage and Family 79: 1224-1240.

Ryan W. 1976. Blaming the Victim New York Vintage

Rylko-Bauer B, Farmer P. 2016. Structural Violence, Poverty, and Social Suffering. In The Oxford Handbook of the Social Science of Poverty, ed. D Brady, LM Burton, pp. 47-74. Oxford University Press

Salehi-Isfahani D, Mostafavi-Dehzooei MH. 2018. Cash Transfers and Labor Supply: Evidence from a Large-Scale Program in Iran. Journal of Development Economics 135: 349-367

Sawhill I. 2003. The Behavioral Aspects of Poverty. Public Interest. 153 (Fall): 79-93 1988. Poverty in the U.S.: Why Is It So Persistent? Journal of Economic Literature. 26: 1073-1119

Schwartz S, Carpenter KM. 1999. The Right Answer for the Wrong Question: Consequences of Type III Error for Public Health Research. American Journal of Public Health 89: 11751180

Scruggs L, Allan JP. 2006. The Material Consequences of Welfare States: Benefit Generosity and Absolute Poverty in 16 OECD Countries. Comparative Political Studies. 39: 880-904

Seim J. 2017. The Ambulance: Toward a Labor Theory of Poverty Governance. American Sociological Review. 82: 451-475

Sen A. 1999. Development As Freedom. New York: Anchor Books

Shaefer HL. 2010. Identifying Key Barriers to Unemployment Insurance for Disadvantaged Workers in the U.S. Journal of Social Policy. 39: 439-460

Sharkey P. 2013. Stuck in Place. University of Chicago Press

Small ML, Harding DJ, Lamont M. 2010. Reconsidering Culture and Poverty. Annals of American Academy of Political and Social Science. 629: 6-27

Sosnaud B. 2016. Living Wage Ordinances and Wages, Poverty, and Unemployment in US Cities. Social Service Review. 90: 3-34.

Soss J, Fording RC, Schram SF. 2011. Disciplining the Poor. Chicago: University of Chicago Press

Steinberg S. 2011. Poor Reason: Culture Still Doesn’t Explain Poverty. Boston Review. January 13.

Streib J, Verma S, Welsh W, Burton LM. 2016. Life, Death and Resurrections: The Culture of Poverty Perspective. In The Oxford Handbook of the Social Science of Poverty, ed. D Brady, LM Burton, pp. 247-269. Oxford University Press

Stuart, Forrest. 2016. Down, Out, and Under Arrest. Chicago: University of Chicago Press Sugrue TJ. 1996. The Origins of the Urban Crisis. Princeton, NJ: Princeton University Press

Sullivan E. 2017. Displaced in Place: Manufactured Housing, Mass Eviction, and the Paradox of State Intervention. American Sociological Review. 82: 243-269

Tach L, Emory AD. 2017. Public Housing Redevelopment, Neighborhood Change, and the Restructuring of Urban Inequality. American Journal of Sociology. 123: 686-739 
Tomaskovic-Devey D. 1991. A Structural Model of Poverty Creation and Change: Political Economy, Local Opportunity, and U.S. Poverty, 1959-1979. Research in Social Stratification and Mobility. 10:289-322

Turney K. 2015. Paternal Incarceration and Children's Food Insecurity: A Consideration of Variation and Mechanisms. Social Service Review 89: 335-367.

Vaisey S. 2010. What People Want: Rethinking Poverty, Culture, and Educational Attainment. Annals of the American Academy of Political and Social Science. 629: 75-101

Vandecasteele L. 2011. Life Course Risks or Cumulative Disadvantage? The Structuring Effect of Social Stratification Determinants and Life Course Events on Poverty Transitions in Europe. European Sociological Review. 27: 246-263

Wacquant L. 2009. Punishing the Poor Durham, NC: Duke University Press.

Watkins-Hayes C, Kovalsky E. 2016. The Discourse of Deservingness: Morality and the Dilemmas of Poverty Relief in Debate and Practice. In The Oxford Handbook of the Social Science of Poverty, ed. D Brady, LM Burton, pp. 193-220. Oxford University Press

Wildeman C. 2014. Parental Incarceration, Child Homelessness, and the Invisible Consequences of Mass Imprisonment. Annals of the American Academy of Political and Social Science 651: 74-96.

Wilson WJ. 1996. When Work Disappears. New York: Knopf 1987. The Truly Disadvantaged. Chicago: University of Chicago Press

Wodtke GT. 2013. Duration and Timing of Exposure to Neighborhood Poverty and the Risk of Adolescent Parenthood. Demography. 50: 1765-1788 
Panel A. Behavioral Theories

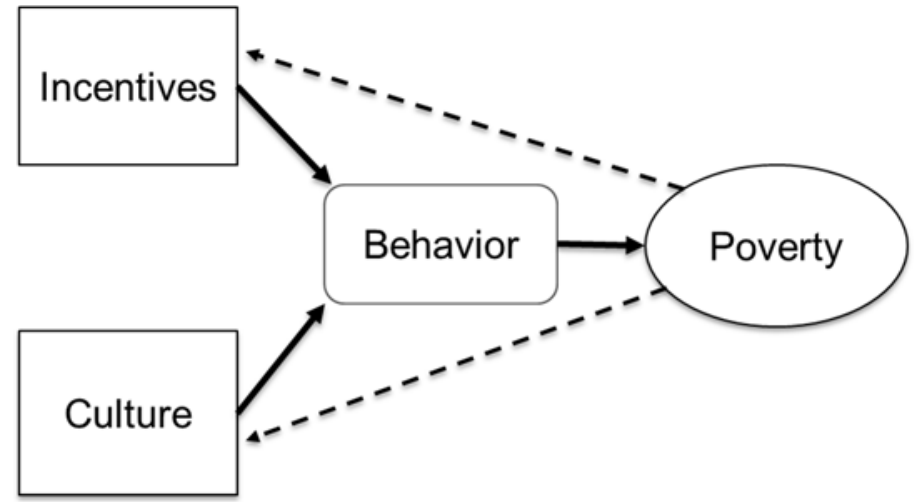

Panel B. Structural Theories

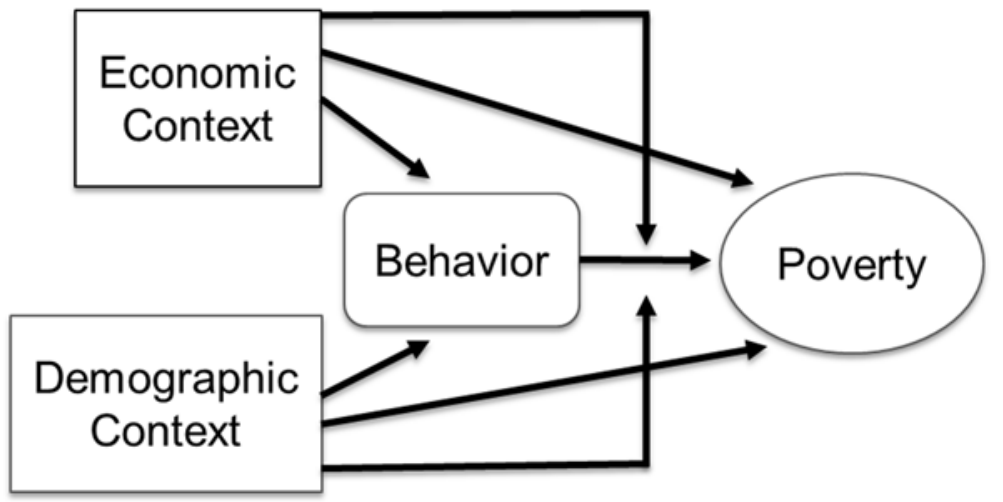

Panel C. Political Theories

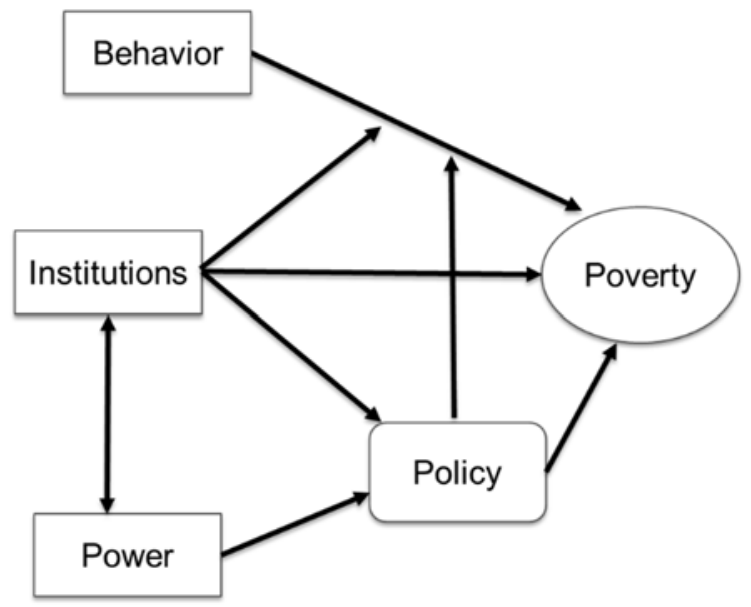

Figure 1. Conceptual Models of Causal Relationships in Three Theories of Poverty 


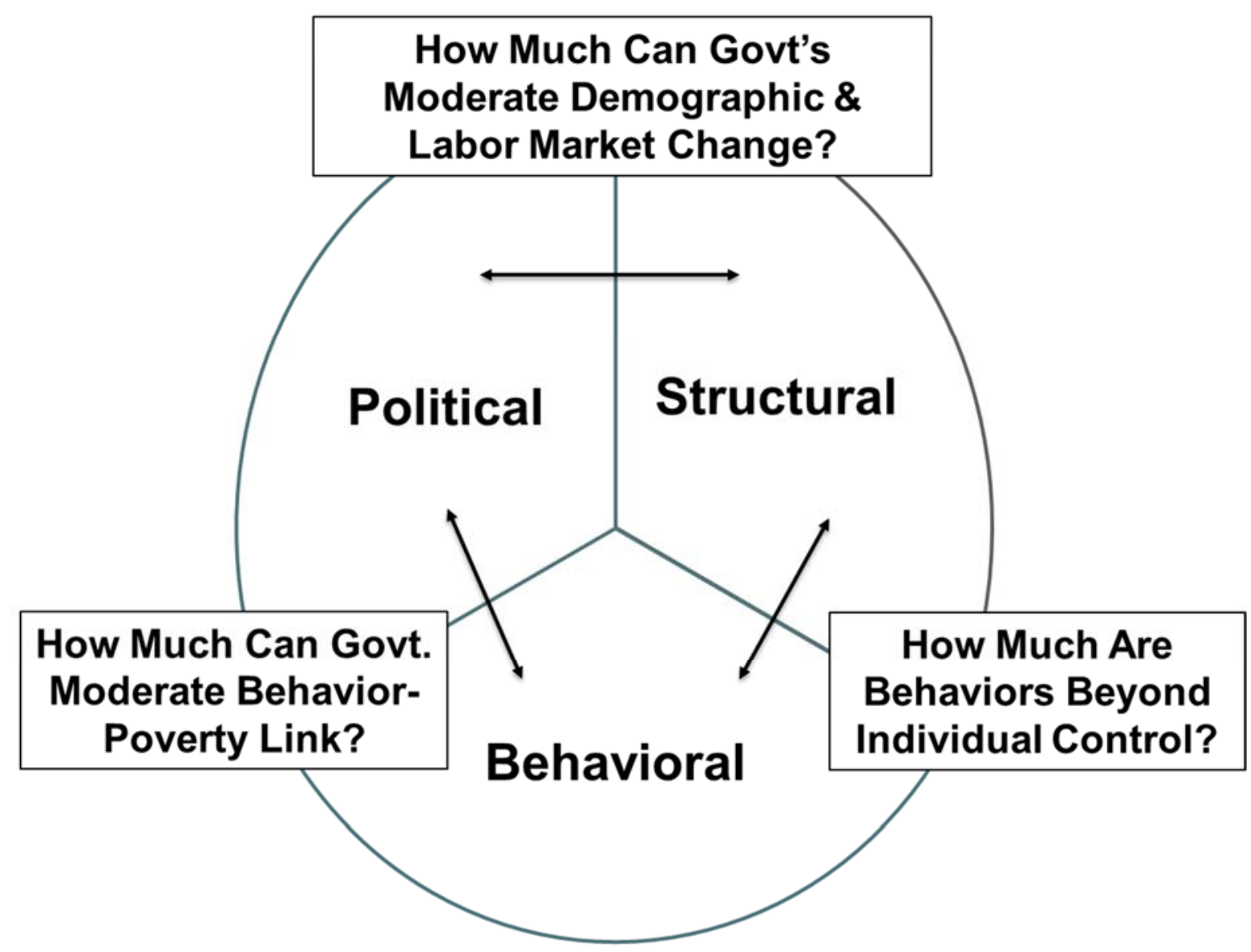

Figure 2. Distinguishing Between Theories 